\title{
ANALYSIS
}

\section{The impact of offering two versus three alternatives in choice modelling experiments}

\author{
John Rolfe, $e^{a, *}$, Jeff Bennett ${ }^{b}$ \\ ${ }^{\mathrm{a} C e n t r e ~ f o r ~ E n v i r o n m e n t a l ~ M a n a g e m e n t, ~ C e n t r a l ~ Q u e e n s l a n d ~ U n i v e r s i t y, ~ R o c k h a m p t o n, ~ Q L D ~ 4702, ~ A u s t r a l i a ~}$ \\ ${ }^{\mathrm{b}}$ Crawford School of Economics and Government, The Australian National University, Canberra ACT 0200, Australia
}

\section{A R T I C L E D A T A}

Article history:

Received 30 December 2006

Received in revised form

1 August 2008

Accepted 1 August 2008

Available online 22 September 2008

Keywords:

Choice modelling

Choice alternatives

Serial non-participation

Design dimensions

\begin{abstract}
A B S T R A C T
Researchers designing choice modelling experiments have some latitude over the number of choice alternatives that can be offered in each choice set. There is some evidence that design dimensions, including the number of alternatives available in each choice set, can influence model outcomes. A key issue is whether referendum formats with binary options are preferable to choice sets with multiple alternatives.

A choice modelling experiment was performed where questionnaires delivered to two split samples differed only according to whether two or three alternatives were offered to respondents in each choice set. The results indicate that more robust models could be constructed from the three-alternative split compared to the two-alternative split. One reason for the difference is that respondents tended to display serial non-participation in the two-alternative format, choosing an alternative consistently without regard for changes in the attributes. For practitioners of the $\mathrm{CM}$ technique, the results suggest that it may be preferable to offer more than two alternatives in a choice set that includes a status quo option.
\end{abstract}

(c) 2008 Elsevier B.V. All rights reserved.

\section{Introduction}

Choice modelling ${ }^{1}$ (CM) has been developed as a stated preference technique capable of estimating values for changes in resource use where data are not available from markets (Louviere et al., 2000; Bennett and Blamey, 2000). While it shares some similarities with the contingent valuation method (CVM), CM involves the use of multiple choice sets that are distinguished by variations in the levels of underlying attributes. Advantages of the CM technique over the CVM include the ability to frame complex tradeoffs to respondents, and ability to generate a richer set of results that allow better understanding and prediction of respondent behaviour.
A key design issue in the development of a CM application is determining the number of alternative choice profiles that should be offered in each choice set (Caussade et al., 2005; Hensher, 2006). While there are usually two alternatives offered in a dichotomous (referendum) CVM format, reflecting the options, CM experiments may involve multiple alternatives being offered in a single choice set. Respondents are asked to choose a preferred option, which includes a 'status quo' or 'no-choice' alternative to avoid forcing responses. While the latter typically has a zero payment level, the other alternative(s) have some payment level attached to identify the monetary cost involved and allow subsequent value estimation.

\footnotetext{
* Corresponding author. Faculty of Business and Informatics, Central Queensland University, Rockhampton, Qld, 4702, Australia. Tel.: +61 7 49232 132, +61 427130811 (mobile); fax: +61 749309700.

E-mail address: j.rolfe@cqu.edu.au (J. Rolfe).

${ }^{1}$ These are also known as discrete choice experiments or choice-based conjoint analysis.
} 
In some cases it is realistic to frame a CM application in the dichotomous choice format with only two options (Breffle and Rowe, 2002). These might apply to proposals where the key policy issue is whether to accept an exogenously specified proposal or not. The referendum CVM format appears to map well to these policy issues. For other policy issues, there is a wider range of potential outcomes, and the analytical task is to identify a preferred outcome or an underlying model of community preferences that allows different alternatives to be evaluated. CM is suited to this purpose, with the different combinations (factorial) of attributes, labels and levels included in a choice set mapping to different policy options. From the presentation of a select number of different policy options and the subsequent modelling of respondent choices, evaluations can be performed across a more comprehensive range of potential options (Bennett and Blamey, 2000).

While CM is designed for application to policy issues where there is variation in potential outcomes, the number of alternative choices offered to respondent in each choice set is typically limited. This is to avoid burdening respondents with complex choices (Swait and Adamowicz, 2001; Breffle and Rowe, 2002; Caussade et al., 2005), and to minimize the size of the fractional factorial experimental design (Louviere et al., 2000). In CM, cognitive burdens are also typically assumed to be reduced by describing choice profiles with a limited number of attributes and levels, and blocking experimental designs into smaller sets so that respondents are only presented with a limited number of choice sets (Hensher, 2006).

The analyst designing a CM application typically has some discretion over the number of choice alternatives and choice sets that are presented to survey respondents (Louviere et al., 2000; Hensher, 2006). In most cases the analyst balances the desire to make choice sets realistic (including more alternatives, attributes, levels and labels) against the desire to minimize choice complexity (reducing the number of alternatives, attributes, levels and labels). In cases where respondent knowledge and understanding is limited, and/or where individual profiles are complex because of the number of attributes and levels involved, there is a tendency to reduce the number of profiles offered in a choice set so as to limit the cognitive task involved. While focus groups and pretests are important ways of guiding a CM design, the process remains the combination of logic, experience and empirical detective work as described by Carson et al. (1994) and Louviere et al. (2000).

There have been several areas of developing interest centering on the influence of design dimensions on the results of stated choice experiments. One area of focus is how the structure of a CM experiment influences the complexity and cognitive burden placed on respondents, with subsequent impacts on the accuracy of estimated models (Dellaert et al., 1999; Swait and Adamowicz, 2001; Hensher, 2004; Caussade et al., 2005; Hensher, 2006). Another area of interest is how design may generate problems of serial non-participation, where individual respondents choose the 'status quo' or 'nochoice' option for every choice occasion (Van Haefen et al., 2005). A related issue is the potential for a dichotomous choice format to generate polarized responses in CVM experiments (Scarpa and Willis, 2006), perhaps because of the way that choices are forced on respondents (Dhar and Simpson, 2003). Johnson (2006) summarizes these two broad approaches to the influence of design dimensions as focusing on statistical and cognitive efficiency issues.

The focus of the research reported in this paper is to explore how a single design dimension, the number of alternatives offered, can affect the outcomes of a CM experiment in terms of both statistical model outputs and levels of serial non-participation. This has been done by performing two split samples of a CM application. One split sample involved respondents being given choices between two alternatives in a referendum-style format, while the other had respondents making choices between three alternatives. The paper is organized in the following way. Background literature relating to the number of choice alternatives and serial non-participation is reviewed in Section 2, followed by details of the design and conduct of the experiment in Section 4 , followed by discussion and conclusions in Sections 5 and 6.

\section{Background literature and hypotheses}

The theory underlying CM assumes that respondents choose the alternative in each choice set that yields them the highest utility (Louviere et al., 2000). Random utility theory provides the conceptual framework where the utility of an alternative is divided into a systematic (explainable) component and a random error component. The latter is used to capture unexplained variations in consumer choice behaviour, and assumptions about the distribution of the random error term underlie the statistical models generated from the choice data.

Implicit in the application of the random utility model and the traditional notion of value maximization used in economics is that participants complete choice sets as utility maximisers, and approach each of the repeated tasks in a similar manner (Swait and Adamowicz, 2001). While researchers have been grappling with the potential effects of choice complexity, fatigue and the use of heuristics, there has been limited development of analytical models to explore these issues (Swait and Adamowicz, 2001; Caussade et al., 2005). One of the more promising approaches is to treat choice processes as optimization problems where decision makers will employ different strategies to help form preferences and make choices.

Heiner (1983) and Mazzotta and Opaluch (1995) postulate that the choice of decision strategies is partly dependent on the complexity of issues facing respondents. Dhar (1997) and Dhar and Simpson (2003) argue that increasing the complexity of decision environments is more likely to encourage the use of simplifying heuristics, and may result in individuals deferring or avoiding choices. This means that researchers have to consider decision processes as contributing factors to parameter and variance estimates (Mazzotta and Opaluch, 1995; Breffle and Rowe, 2002; Hensher, 2006; Louviere, 2006). There have been a number of approaches to testing these issues with CM experiments, which can be broadly classified into three groups.

The first approach involves the conduct of split sample CM experiments, where parallel studies are conducted that only differ by one or more design dimensions. For example, Dellaert 
Table 1 - Attributes and levels used in both split samples

\begin{tabular}{llcccc} 
Alternative & Cost & $\begin{array}{c}\text { Healthy vegetation left in } \\
\text { floodplains (\%) }\end{array}$ & $\begin{array}{c}\text { Kilometers of healthy } \\
\text { waterways }\end{array}$ & $\begin{array}{c}\text { People leaving country } \\
\text { areas each year }\end{array}$ & $\begin{array}{c}\text { Amount of water left in } \\
\text { reserve (\%) }\end{array}$ \\
\hline $\begin{array}{l}\text { Constant } \\
\text { base }\end{array}$ & $\$ 0$ & 20 & 1100 & 0 & 0 \\
Alternatives & $\$ 20$ & 25 & 1200 & 5 & 4 \\
& $\$ 50$ & 30 & 1400 & 25 & 8 \\
& $\$ 100$ & 35 & 1600 & 15 & 12 \\
\hline
\end{tabular}

et al. (1999) ran three split sample experiments to test the effect of shifts in attribute pricing levels on choice consistency. More sophisticated versions of this approach where five design dimensions were varied systematically across 16 versions of a CM survey are reported by Caussade et al. (2005) and Hensher (2006).

The second approach involves the use of different discrete choice modelling alternatives to the standard multinomial logit (MNL) approach. These allow the distribution of error terms to vary across groups of choices (nested logit), or across alternatives (heteroskedastic variance (HEV) models), essentially modelling different decision tree approaches to the selection of preferred alternatives under varying levels of complexity. DeShazo and Fermo (2002) analysed the effects of different levels of complexity on respondents with the use of HEV models, showing that increased complexity of choice sets affected choice consistency. Caussade et al. (2005) employed HEV models to test the effect of different design dimensions, including the number of alternatives, on respondent choices. They found that while all design dimensions tested affected the consistency of choices, as measured by choice variance, they did not find systematic effects on willingness to pay estimates.

The third approach to testing these issues with CM experiments is to relax the assumption that preferences are held consistently across respondents (Holmes and Adamowicz, 2003). Swait and Adamowicz (2001) employ latent class models to test how different classes of consumers may change decision strategies when faced with different levels of task complexity. Their results show that as the level of complexity rises (including increases in the number of alternatives), consumers were more likely to adopt simpler processing strategies. Hensher (2004) employed mixed logit models to identify that stated choice design dimensions, including the number of alternatives, was linked to variations in willingness to pay for savings in travel time.
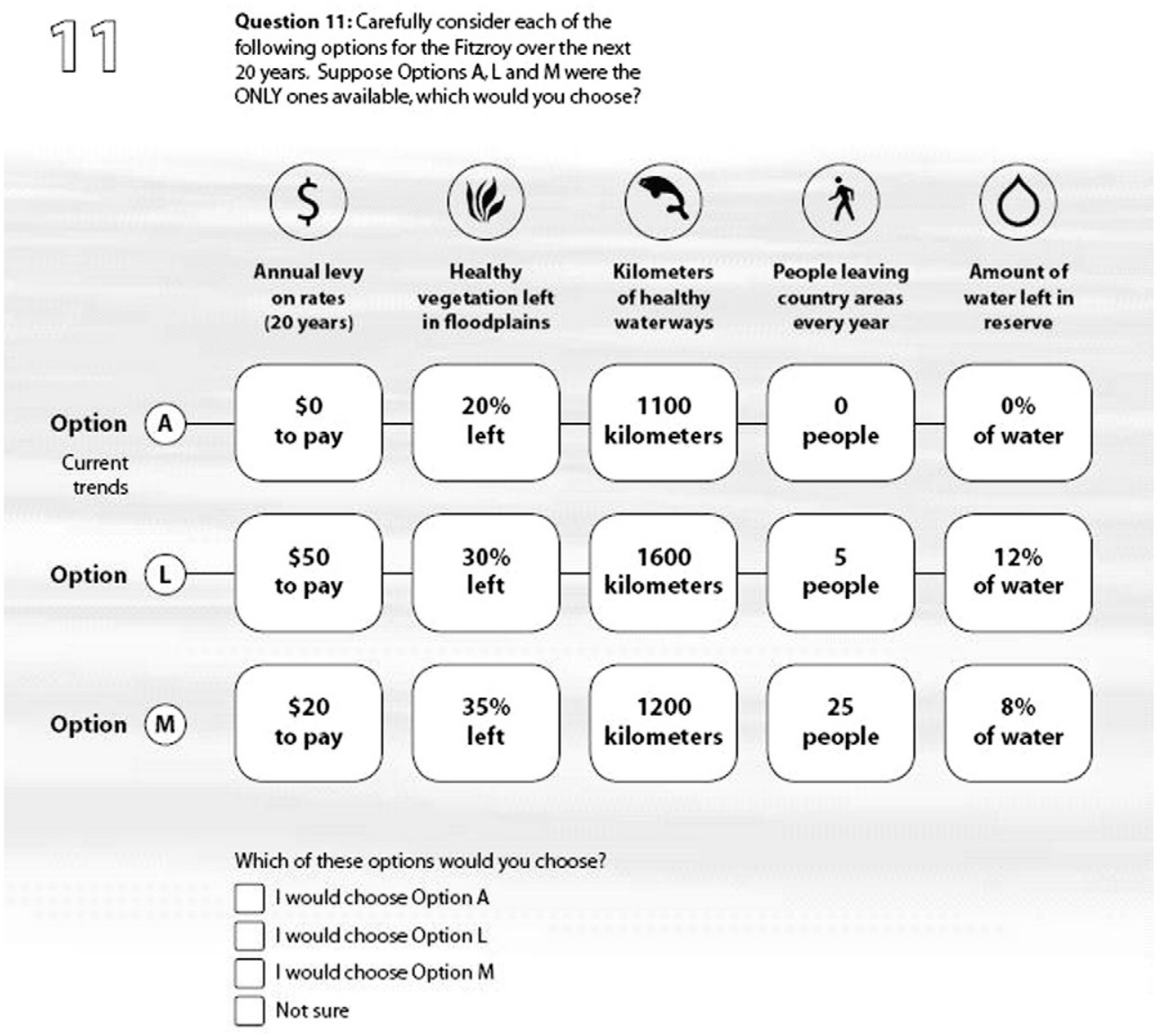

Fig. 1-Example of a choice set in the three-alternative version. 
Respondent characteristics have also been used to predict serial non-participation in choice experiments. The latent class model of Swait and Adamowicz (2001) had better predictive power than MNL models for respondents choosing the 'none' option. Single and double hurdle models were used by Van Haefen et al. (2005) to explain non-participation in choice experiments as a function of demographic variables. While their modelling improved the prediction of nonparticipation, it did not identify whether respondents chose these options because of complexity issues, protest issues or genuine preferences for the status quo options.

The range of studies reviewed indicates that design dimensions may influence the performance and results of stated choice experiments. Caussade et al. (2005:631) indicate that the order of impact of design dimensions of model variance was first, number of attributes; second, number of alternatives; third, range of attribute levels; fourth, number of attribute levels, and last number of choice scenarios (sets). They found that designs with four alternatives had the highest scale parameters, followed by those with five and then three alternatives. This suggests that increasing the number of alternatives to four provides more opportunity for respondents to find a suitable choice, but that increases after that point are sub-optimal because of higher levels of complexity.

Caussade et al. (2005) did not consider a two-alternative option in their study. Such a format could be employed to focus the choice task or to minimize choice complexity. Breffle and Rowe (2002) recommend a two-alternative format when the primary objective is to estimate directly values for a single attribute. An additional advantage of a choice/no-choice format is that it avoids potential violations of the IID conditions in MNL models. When a 'no-choice' alternative is added to several other alternatives, problems in model estimation can arise because the other alternatives are seen as more substitutable than the no-choice option.

Hoehn and Loomis (1993) utilized the two-alternative format to ask a series of referendum CVM questions about wetland protection, while Breffle and Rowe (2002) used both binary improvement and referendum choice formats to explore values for minimizing PCB releases in Green Bay, Wisconsin. In the binary improvement options they gave two improvement profiles and no 'status quo' option, while in the referendum format they used one improvement profile and

Table 2-Socio-economic characteristics of sample respondents

\begin{tabular}{lll} 
Split sample & 1 & 2 \\
\hline $\begin{array}{l}\text { Average age } \\
\text { \% male }\end{array}$ & 40.33 & 39.68 \\
$\begin{array}{l}\text { \% of households with children } \\
\text { \% that are members of an environmental }\end{array}$ & 35 & 36 \\
$\begin{array}{l}\text { organization } \\
\text { \% that are associated with farming interests }\end{array}$ & 11 & 79 \\
$\begin{array}{l}\text { \% with a post-secondary education qualification } \\
\text { \% that tend to favour protection of the }\end{array}$ & 35 & 40 \\
$\begin{array}{l}\text { environment over development } \\
\text { \% that tend to favour development over }\end{array}$ & 36 & 39 \\
$\begin{array}{l}\text { protection of the environment } \\
\text { Average income }\end{array}$ & 5 & 5 \\
\hline
\end{tabular}

Table 3 - Variables used as regressors in CM models

\begin{tabular}{|c|c|}
\hline Variables & Description \\
\hline Cost & $\begin{array}{l}\text { Amount that households would pay in extra rates } \\
\text { (or rent) each year to fund improvements }\end{array}$ \\
\hline Vegetation & $\%$ of healthy vegetation remaining in floodplains \\
\hline Waterways & $\begin{array}{l}\text { Kilometers of waterways in catchment remaining in } \\
\text { good health }\end{array}$ \\
\hline $\begin{array}{l}\text { People } \\
\text { leaving }\end{array}$ & Number of people leaving country areas each year \\
\hline Reserve & $\begin{array}{l}\% \text { of water resources in catchment not committed to } \\
\text { the environment or allocated to industry/urban/ } \\
\text { irrigation uses }\end{array}$ \\
\hline Age & Age of respondent (in years) \\
\hline Member & $\begin{array}{l}\text { Dummy coded ( } 1 \text { if member of organization } \\
\text { associated with environmental conservation) }\end{array}$ \\
\hline Education & $\begin{array}{l}\text { Dummy coded ( } 1 \text { if respondent has post-secondary } \\
\text { qualification) }\end{array}$ \\
\hline Income & Income of respondent \\
\hline Gender & Dummy coded (1 if respondent was male) \\
\hline Farming & $\begin{array}{l}\text { Dummy coded ( } 1 \text { if respondent or family member } \\
\text { associated with farming) }\end{array}$ \\
\hline
\end{tabular}

the 'status quo' option. Breffle and Rowe (2002) found the binary improvement format superior to the referendum format, attributing this to differences in realism and choice complexity.

Adamowicz et al. (2005) reported the use of both twoalternative and three-alternative formats to ascertain the value of health risk reductions to Canadians in the context of clean and safe drinking water. The results demonstrate important differences between the versions, with respondents in the three-alternative version being more likely to choose a status quo option. However, they were unable to identify a reason why the two formats generated different response patterns.

The available literature presents mixed evidence about the desirability of using two-alternative formats in choice experiments. The research question to be addressed in this paper is whether the estimated models from CM experiments are the same where choices are presented in a two-alternative (referendum) or a three-alternative format. The question can be tested by checking if choice behaviour, represented by serial non-participation, model variance and model parameters, varies between the formats.

\section{Design and conduct of the experiments}

The research question was addressed in the design and application of two split samples of a CM experiment. The experiment was focused on the estimation of values for the environmental and social impacts of further water resource development in the Fitzroy Basin of Queensland, Australia. The two split samples used questionnaires that involved two and three-alternative choice sets respectively.

The Fitzroy Basin is the second largest externally-draining basin in Australia. Agriculture is an important industry in the basin, and irrigation water is used to grow cotton and other crops. Potential exists to divert more water for agricultural and industry use, but there are likely to be environmental impacts associated with such development. On the other hand, there 
Table 4 - MNL models for each survey

\begin{tabular}{|c|c|c|c|c|c|c|}
\hline \multirow[t]{2}{*}{ Variable } & \multicolumn{2}{|c|}{ Two-alternative } & \multicolumn{2}{|c|}{$\begin{array}{l}\text { Two-alternative } 2 \text { alternative } \\
\text { with interaction }\end{array}$} & \multicolumn{2}{|c|}{ Three-alternative3 alternative } \\
\hline & Coefficient & Standard error & Coefficient & Standard error & Coefficient & Standard Error \\
\hline ASC (constant) & $1.5759^{* * *}$ & 0.4710 & $0.8855^{*}$ & 0.5250 & $2.919^{* * *}$ & 0.446 \\
\hline Cost & $0.0117^{* * *}$ & 0.0023 & $-0.0981^{* * *}$ & 0.0358 & $-0.018^{* * *}$ & 0.002 \\
\hline Vegetation & -0.0063 & 0.0186 & $-0.2006^{* * *}$ & 0.0659 & $0.051^{* * *}$ & 0.016 \\
\hline Water & $0.0008^{*}$ & 0.0004 & $0.0025^{* * *}$ & 0.0007 & $0.001^{* *}$ & 0.000 \\
\hline People leaving & -0.0032 & 0.0091 & $0.0309^{* *}$ & 0.0142 & $-0.016^{* *}$ & 0.008 \\
\hline Reserve & -0.0124 & 0.0219 & 0.0012 & 0.0224 & $0.106^{* * *}$ & 0.020 \\
\hline Cost $\times$ vegetation & & & $0.0037^{* * *}$ & 0.0012 & & \\
\hline ASC $\times$ age & $-0.0145^{* * *}$ & 0.0047 & $-0.0146^{* * *}$ & 0.0047 & $-0.021^{* * *}$ & 0.006 \\
\hline ASC $\times$ member & 0.2719 & 0.2978 & 0.2708 & 0.2982 & $-3.196^{* * *}$ & 1.041 \\
\hline ASC $\times$ education & 0.0790 & 0.1488 & 0.0771 & 0.1496 & $-0.660^{* * *}$ & 0.171 \\
\hline ASC $\times$ income & $0.0416^{* *}$ & 0.0209 & $0.0420^{* *}$ & 0.0210 & $0.000^{* * *}$ & 0.000 \\
\hline ASC $\times$ gender & $-0.4092^{* * *}$ & 0.1446 & $-0.4147^{* * *}$ & 0.1455 & $0.457^{* * *}$ & 0.167 \\
\hline ASC $\times$ farming & $-0.3948^{* *}$ & 0.1701 & $-0.4006^{* *}$ & 0.1712 & $-0.654^{* * *}$ & 0.234 \\
\hline \multicolumn{7}{|l|}{ Model statistics } \\
\hline$N$ (choice sets) & & 1164 & & 1164 & & 888 \\
\hline Skipped observations & & 252 & & 252 & & 104 \\
\hline Log likelihood & & -584.76 & & -579.90 & & -697.78 \\
\hline Adjusted rho-square & & 0.06263 & & 0.0639 & & 0.18362 \\
\hline Chi-square (DoF) & & 58.22 & & $67.94(12)$ & & $235.37(11)$ \\
\hline
\end{tabular}

are likely to be some social benefits of increasing agricultural production in rural areas where population declines are occurring. An assessment of community values is needed to be able to perform a full cost benefit analysis of options to develop more water resources and intensify agricultural production. Because non-use values are involved, a stated preference technique such as $\mathrm{CM}$ is appropriate for this purpose.

A key focus of the design was to minimize the differences between the split samples, apart from the number of alternatives on offer in the choice sets. For the experiment, the same attributes and levels were used to describe the scenarios (Table 1), and the same background material to frame the choices was used. In both cases, the constant base used was a future scenario, reflecting the expected levels of environmental and social attributes in twenty years time, based on current trends. The alternative(s) offered provided a potential improvement that came with a monetary cost consequence.

A single experimental design ${ }^{2}$ with 24 choice sets was used for the two split sample questionnaires, except that one set of the alternatives was dropped for the two-alternative version. In an effort to keep the choice task constant across the split samples, respondents in the two-alternative version completed 12 choice sets, while respondents in the threealternative version completed 8 choice sets (Fig. 1). This ensured that respondents in each split sample were presented with 24 choice alternatives. The experimental design was partitioned (blocked) to provide the required number of choice sets for each split sample version.

\footnotetext{
${ }^{2}$ An orthogonal fractional factorial design was used to generate 25 choice sets for the five attributes, three levels and two alternatives involved. One dominated choice set was dropped to leave 24 choice sets.
}

A potential weakness with this approach was that the experimental design in the two-alternative version was essentially driven by the design used for the three-alternative version, with potential implications for design efficiency. To test this, $D$-errors were calculated for both experimental designs against a set of prior attribute coefficients derived from a similar survey conducted the previous year (Rolfe et al., 2006). The average correlation between attribute levels was $8.8 \%$ in the two-alternative version compared to $7.0 \%$ in the three-alternative version. The $D$-error for the experimental design used in the two-alternative version was $13.8 \%$ higher that the corresponding $D$-error for the three-alternative survey ${ }^{3}$. This indicated that while there was some loss of efficiency in using the same design as the base for both experiments, the efficiency losses were not expected to be high.

A drop-off and pick-up approach was used to distribute and collect the questionnaires in Brisbane, the capital city of Queensland. Respondents were sampled at random based on a cluster sampling technique. Nodes were chosen at random in the city, and then some selection rule was used to pick residences (e.g. every 3rd residence in every 5th street). Each survey collector was provided with a set of instructions about how to verbally introduce the questionnaire, and made a minimum of two attempts to collect each one distributed. The questionnaires were collected in May and June 2002.

A total of 341 households were invited to participate from the Brisbane population of approximately 1.6 million people. A total of 208 questionnaires were fully completed (97 surveys for the two-alternative version and 111 surveys for the threealternative version). Of all people approached, $61 \%$ gave back a

\footnotetext{
${ }^{3}$ The $D$-error statistic for the three-alternative experimental design was 0.00157 , while the D-error statistic for the twoalternative model was 0.00178 .
} 
Table 5 - Part-worths and $95 \%$ confidence intervals

\begin{tabular}{|c|c|c|c|c|}
\hline & \multicolumn{2}{|c|}{$\begin{array}{c}\text { Two-alternative } \\
\text { model (with } \\
\text { interaction) }\end{array}$} & \multicolumn{2}{|c|}{$\begin{array}{c}\text { Three-alternative } \\
\text { model }\end{array}$} \\
\hline & $\begin{array}{l}\text { Part- } \\
\text { worth }\end{array}$ & $\begin{array}{c}95 \% \\
\text { Confidence } \\
\text { interval }\end{array}$ & $\begin{array}{l}\text { Part- } \\
\text { worth }\end{array}$ & $\begin{array}{c}95 \% \\
\text { Confidence } \\
\text { interval }\end{array}$ \\
\hline Vegetation & $-\$ 2.045$ & $-\$ 1.672--\$ 2.861$ & $\$ 2.891$ & $\$ 1.000-\$ 5.046$ \\
\hline Waterways & $\$ 0.025$ & $\$ 0.054-\$ 0.016$ & $\$ 0.056$ & $\$ 0.015-\$ 0.101$ \\
\hline $\begin{array}{l}\text { People } \\
\text { leaving }\end{array}$ & $\$ 0.315$ & $\$ 0.592-\$ 0.063$ & $-\$ 0.895$ & $-\$ 1.824--\$ 0.131$ \\
\hline Reserve & Not Sig. & & $\$ 5.949$ & $\$ 3.06-\$ 9.066$ \\
\hline
\end{tabular}

fully completed questionnaire, while $25 \%$ of all people approached declined to complete one, and $14 \%$ of people approached took a questionnaire and either did not return it to the collector or did not complete it fully. Socio-economic characteristics of the different split sample groups are presented in Table 2. T-tests were used to show that there were no significant differences between the respondents for the two groups.

\section{Analysis of results}

The data from the surveys were analysed with the Limdep software package. In the choice sets, respondents were given a "not sure" category to allow for uncertainty as well as the alternatives set out in the choice set. The "not sure" responses were coded to the "no pay" Constant Base alternatives in each choice set ${ }^{4}$. To allow comparison between the split samples, conditional MNL models were estimated. These models relate the choices made to the levels of each attribute in the choice sets, with socio-demographic factors (Table 3 ) and an alternative specific constant (ASC) also interacted with the "no pay" Constant Base alternative. The results of the models across the two split samples are shown in Table 4.

The results demonstrate that the models estimated for the two-alternative choice sets are less robust than models from the three-alternative choice sets, with lower values for the Adjusted Rho-square term. In the initial model, only two attributes (Cost and Water) were significant, with the former inappropriately signed. An interaction term between Cost and Vegetation had to be added to the model to improve explanatory power. Even then, the Reserve attribute was not significant, and the coefficients for Vegetation and People Leaving were not signed as expected.

In contrast, a highly significant model was estimated for the three-alternative data. In the latter case, the chi-square statistic for model significance is high, most attributes are significant at the $1 \%$ level, and attributes and Income are

\footnotetext{
${ }^{4}$ Treatment of the 'not sure' responses follows the logic of offering respondents in referenda CVM multiple choice options even though only two alternatives are on offer (Blamey, Bennett and Morrison 1999). The multiple choice formats are normally seen as giving respondents more options to express their NO vote.
}

signed as expected. For example, the likelihood of choice is increased if there are larger amounts of Vegetation and Waterways protected, and more water is held in Reserve. As expected, increases in Cost or People Leaving were negatively associated with choice. Respondents who were older, female, had higher education levels, and/or higher income levels were more likely to choose a protection option.

\section{Discussion}

The results shown in Table 4 indicate that there are differences between the models estimated from the two survey formats. The differences are summarized in the partworths for the key attributes, with confidence intervals estimated using the Krinsky-Robb procedure ${ }^{5}$ (Table 5). While both models produce similar values for marginal changes in Vegetation and People Leaving, the two-alternative model did not generate significant values for Reserve or appropriately signed values for Waterways. In contrast, the three-alternative split sample has generated a highly significant explanatory model.

The key issue of interest is why the different formats produced variations in the fit and performance of the statistical models. The split sample experiments were designed to be consistent in the attributes and levels used, in the information provided, in the presentation of the survey and in the collection process. As well, there were no significant differences between the characteristics of respondents from the split sample groups, minimal differences in the efficiency of the experimental designs involved, and only slight differences in the amount of information collected ${ }^{6}$.

A preliminary step was to identify if any structural issues could have generated differences. One identifiable difference between the split samples is the number of choice sets presented. The evidence presented by Caussade et al. (2005) is that the number of choice scenario exercises can influence the variance of responses. To explore this possibility, responses for the first eight choice sets in the two-alternative surveys were analysed separately. There was no improvement in the number of significant parameters between the models based on eight compared to twelve choice sets. A Poe et al. (2005) test revealed no significant difference between the eight and the twelve choice set models. This implies that the underlying choice behaviour of respondents is creating the model differences rather than the number of choice sets.

To understand how the different formats could have generated variations in choice behaviour, the pattern of responses across attribute levels and choice alternatives was identified. The relationship between the choices made and the

\footnotetext{
${ }^{5}$ This involves the simulation of an asymptotic distribution of the coefficients that are generated in a CM experiment, from which confidence intervals can then be computed (Krinsky and Robb 1986).

${ }^{6}$ Although both split-samples faced the same number of choice alternatives (24), more information was effectively collected in the three-alternative version because there were fewer 'constant base' alternatives (8) compared to the two-alternative version (12).
} 
levels of the attributes on offer for the two-alternative data set is shown in Fig. 2. This identifies that there was a difference between the choices made for the base option compared to the alternative option (significant at the $1 \%$ level). However, there was no significant relationship between the choices made and the levels of the attributes in the alternatives, explaining the non-significance of the attributes in the estimated model. It would normally be expected that the percent of alternatives chosen would decrease as cost levels increased, and increase for increases in the levels of the other variables. The results suggest that respondents evaluated choices between the status quo and an improvement, but did not distinguish between various levels of an improvement on offer.

The variation in responses between the status quo and the alternatives in the two-alternative version suggests it might be possible to analyse the response as a simple binary choice, as if they were referendum CVM responses. The choice pattern illustrated in Fig. 2 indicates that the cost of the alternative may have been a dominant attribute, given the preference for the cheaper status quo option. If the other attributes had been more important, the alternative option should have been more frequently preferred in each choice set.

The choices made in the two-alternative version can be analysed as CVM data by taking data from a single choice set (where only one cost level is available), or by taking data from all the choice sets (where there are confounding influences from the non-cost attributes). In each case, the logit model was used only to identify the relationship between the choice made and the cost of the alternative presented. The results, shown in Table 6, demonstrate that the data can be used to generate significant CVM models. The lower model fit for the full data set indicates that the variation in the non-cost attributes is confounding the statistical relationship.

These results indicate that while the two-alternative format with a constant base may be an appropriate format in CVM applications, it may not be as appropriate for some CM applications. The reasons appear to be related to the underlying choice behaviour. In this case study there was a large proportion of fixed choices and serial non-participation in the two-alternative versions of the questionnaires. These are responses that appear invariant to the scale of the good being offered; i.e. respondents have consistently chosen a status quo

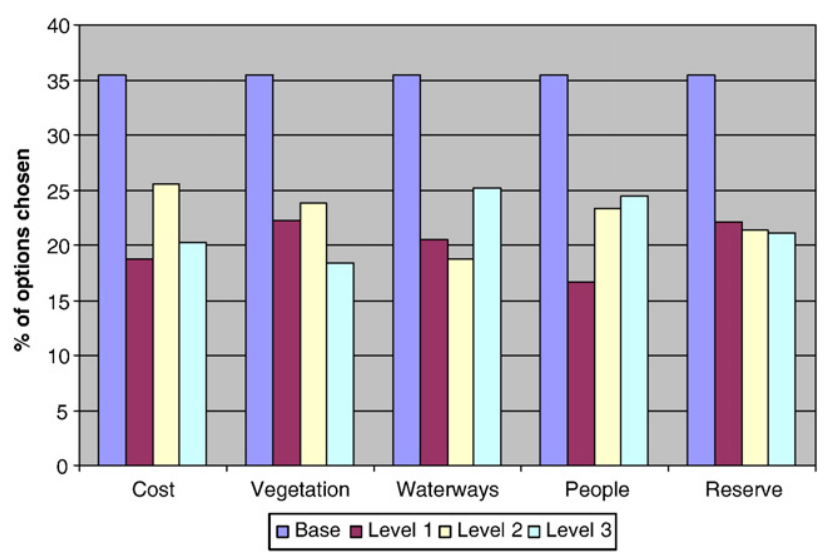

Fig. 2-Percent of choices made by attribute levels in the twoalternative version.

\begin{tabular}{|c|c|c|c|c|}
\hline \multirow[t]{2}{*}{ Variable } & \multicolumn{2}{|c|}{ 1st choice set } & \multicolumn{2}{|c|}{12 choice sets } \\
\hline & Coefficient & $\begin{array}{l}\text { Standard } \\
\text { error }\end{array}$ & Coefficient & $\begin{array}{c}\text { Standard } \\
\text { error }\end{array}$ \\
\hline $\begin{array}{l}\text { ASC } \\
\text { (constant) }\end{array}$ & $1.2862^{* * *}$ & 0.2465 & $0.1361^{* * *}$ & 0.0525 \\
\hline Cost & $-0.1286^{* * *}$ & 0.0174 & $-0.0050^{* * *}$ & 0.0012 \\
\hline \multicolumn{5}{|l|}{ Model statistics } \\
\hline$N$ (choice sets) & & 97 & & 1164 \\
\hline Log likelihood & & -101.35 & & -1604.64 \\
\hline $\begin{array}{l}\text { Pseudo } \\
\text { rho-square }\end{array}$ & & 0.2463 & & 0.0056 \\
\hline $\begin{array}{l}\text { Chi-square } \\
(\mathrm{DoF}=1)\end{array}$ & & 66.24 & & 18.02 \\
\hline
\end{tabular}

${ }^{* * *}=$ significant at $1 \%$ level, ${ }^{*}=$ significant at $10 \%$ level.

or a conservation option no matter the levels of the attributes. Respondents in the two-alternative split sample have tended to choose one alternative consistently, apparently unconcerned about differences between alternatives caused by changes in attribute levels.

The pattern of responses is shown in Table 7. In the twoalternative split, a high proportion of respondents (38\%) always chose the same alternative in the choice sets. Crosstab and chi-square tests showed that these serial non-participants were more likely to be female $(p=0.000)$, a member of an environment organization $(p=0.000)$, not associated with farming $(p=0.003)$, or have a higher level of education $(p=0.000)$. In contrast, only a small proportion of respondents $(4 \%)$ in the three-alternative experiment always chose the same alternative. There is also a difference in the rates of "not sure" responses between the two-alternative and threealternative formats, indicating that providing three rather than two choice alternatives increased the likelihood of respondents being able to select their preferred alternatives ${ }^{7}$.

The evidence from the results shows that the number of choice alternatives had an impact on respondent behaviour. The most direct evidence relates to the changes in response patterns as the number of alternatives offered to respondents vary. The provision of the third choice alternative has reduced the occurrence of fixed choices and serial non-participation. Providing more than two alternatives appears to have 'freed up' the choice behaviour of respondents. Conversely, offering only two alternatives seems to have locked respondents into fixed choice positions, where the underlying attributes of the choice options made little difference to the positions reached.

The reasons underlying the behavioural change are unclear. Offering only two alternatives may have caused respondents to focus on the labels or other key identification features (i.e. development or environment) rather than looking at the levels of the underlying attributes. The referendum format may have polarized preferences in the way that Scarpa

\footnotetext{
${ }^{7}$ Additional models were run where the serial non-participants and/or the 'not sure' responses were excluded from the analysis, but this did not generate more robust models.
} 
Table 7 - Uniform responses chosen

\begin{tabular}{|c|c|c|c|c|c|c|}
\hline \multirow[t]{2}{*}{ Split sample } & \multicolumn{4}{|c|}{ Number of uniform responses chosen } & \multirow{2}{*}{$\begin{array}{c}\text { Total } \\
\text { surveys } \\
\text { collected }\end{array}$} & \multirow{2}{*}{$\begin{array}{c}\% \text { of } \\
\text { uniform } \\
\text { responses }\end{array}$} \\
\hline & Option A (Status quo) & Option B & Option C & Not Sure & & \\
\hline Two-alternative & 16 & 13 & Not applicable & 8 & 97 & 38.1 \\
\hline Three-alternative & 4 & 0 & 0 & 0 & 111 & 3.6 \\
\hline
\end{tabular}

and Willis (2006) suggested can happen in the CVM format. It may also have made it more difficult for some respondents to make choices. As suggested by Dhar (1997), the increased complexity of a forced choice may have resulted in the higher rate of "not sure" responses in the two-alternative split.

The standard expectation is that lowering the numbers of choice alternatives will reduce complexity and cognitive burdens, although it will make it harder for respondents to find suitable choices (Van Haefen et al., 2005; Caussade et al., 2005). However, it appears from this study that condensing options down to two alternatives in the referendum format creates particular difficulties for respondents. One possible reason is that respondents may be reluctant to make dichotomous choices. Condensing issues down to two alternatives may create tradeoff dilemmas between ethical or moral issues that respondents find difficult to deal with (Fishbein and Ajzen, 1975; Blamey, 1998). A further possibility is that the number of alternatives may influence preference construction in poorly understood ways, partly because respondents misunderstand or mistrust the options presented to them (Fischhoff et al., 1999), or because the choice framework does not match reality for respondents (Louviere, 2006).

\section{Conclusions}

The impact of the number of choice alternatives on respondent behaviour has been tested in a two split sample application of a CM experiment focused on valuing environmental and social impacts of further water resource development in the Fitzroy Basin of Australia. To avoid confounding effects and so allow comparative testing, all of the design, presentation and information components of the split sample surveys were held constant, with the number of alternatives presented in the choice sets being allowed to vary. The results demonstrate that there are differences between the twoalternative and three-alterative models, consistent with the outcomes reported by Adamowicz et al. (2005).

Serial non-participation was observed in the responses to the referendum two-alternative option, where most respondents were indifferent to changing levels of the attributes involved, including the costs that they might bear. As well, there was a much higher rate of "not sure" responses in the two-alternative split sample compared to the three-alternative one. This indicates that respondents found it easier to analyse and make choices in the three-alternative format. The results support the findings of Breffle and Rowe (2002) that the referendum format where a constant base is offered with a single alternative appears to be less reliable than other formats.
Some researchers have suggested that serial non-participants may be fundamentally different to participants (Swait and Adamowicz, 2001; Van Haefen et al., 2005). The research presented here suggests otherwise. Serial non-participation appears to be related more to design dimensions rather than the characteristics of survey participants. As Van Haefen et al. (2005) suggest, further research is needed to understand how survey design can help to mitigate these events.

The implications of the results are that condensing complex situations to binary choice formats may sometimes hinder rather than help respondents to evaluate tradeoffs. A number of reasons may account for this, including those relating to perceptions about ethical tradeoffs, and the impact of hidden cues on preference construction. As well, these results imply that there may be methodological reasons why values may differ between dichotomous choice CVM and CM applications. These are topics for further research. While these results are only drawn from one trial, they do have some consistency with other research. For practitioners of the CM technique, the results suggest that it may be preferable to offer more than two alternatives in a choice set that includes a status quo option, particularly when the relevant policy setting has multiple alternatives rather than a binary outcome.

\section{Acknowledgements}

Adam Loch contributed to some of the earlier discussions and design of the research experiments reported in this paper, while Riccardo Scarpa and Victor Adamowicz have made helpful suggestions to improve the analysis. The research has been funded by the Australian Research Council and the Queensland Department of Natural Resources and Mines.

\section{R E F E R E N C E S}

Adamowicz, V., Dupont, D., Krupnick, A., 2005. Willingness to Pay to Reduce Community Health Risks from Municipal Drinking Water, a Stated Preference Study, Working Paper. Department of Rural Economy, University of Alberta.

Bennett, J.W., Blamey, R.K. (Eds.), 2000. The Choice Modelling Approach to Environmental Valuation. Edward Elgar, Cheltenham UK.

Blamey, R.K., 1998. Decisiveness, attitude, expression and symbolic responses in contingent valuation surveys. J. Econ. Behav. Organ. 34, 577-601.

Blamey, R.K., Bennett, J.W., Morrison, M.D., 1999. Yea-saying in contingent valuation surveys. Land Econ. 75 (1), 126-141.

Breffle, W.S., Rowe, R.D., 2002. Choice question formats and natural resource tradeoffs. Land Econ. 78 (2), 298-314. 
Carson, R.T., Louviere, J., Anderson, D., Arabie, P., Bunch, D., Hensher, D., Johson, R., Kuhfeld, S., Steinberg, D., Swait, J., Timmermans, H., Wiley, J., 1994. Experimental analysis of choice. Mark. Lett. 5 (4), 351-368.

Caussade, S., Ortuzar, J., Rizzi, L., Hensher, D., 2005. Assessing the influence of design dimensions on stated choice experiment estimates. Transp. Res. 39 (7), 621-640.

Dellaert, B.G., Brazell, J.D., Louviere, J.J., 1999. The effect of attribute variation on consumer choice consistency. Mark. Lett. 10 (2), 139-147.

DeShazo, J.R., Fermo, G., 2002. Designing choice sets for stated preference methods, the effects of complexity on choice consistency. J. Environ. Econ. Manage. 44 (1), 123-143.

Dhar, R., 1997. Context and task effects on choice deferral. Mark. Lett. 8, 119-130.

Dhar, R., Simpson, I., 2003. The effect of forced choice on choice. J. Mark. Res. 40, 146-160.

Fishbein, M., Ajzen, I., 1975. Beliefs, Attitudes, Intentions and Behaviour. Addison-Wesley, Reading MA.

Fischhoff, B., Welch, N., Frederick, S., 1999. Construal processes in preference assessment. J. Risk Uncertain. 19 (1-3), 139-164.

Heiner, R.A., 1983. The origion of predictable behaviour. Am. Econ. Rev. 73, 560-595.

Hensher, D.A., 2004. Identifying the influence of stated choice design dimensionality on willingness to pay for travel time savings. J. Transp. Econ. Policy 38 (3), 425-446.

Hensher, D.A., 2006. Revealing differences in willingness to pay due to the dimensionalities of stated choice designs, an initial assessment. Environ. Resour. Econ. 34, 7-44.

Hoehn, J., Loomis, J., 1993. Substitution effects in the valuation of multiple environmental programs. J. Environ. Econ. Manage. 25 (1), 56-75.

Holmes, T., Adamowicz, V., 2003. Attribute-based methods. In: Champ, P., Boyle, K., Brown, T. (Eds.), A Primer on Nonmarket Valuation. Kluwer Academic Publishers, Netherlands.
Johnson, F.R., 2006. Comment on 'revealing differences in willingness to pay due to the dimensionality of stated choice designs: an initial assessment'. Environ. Resour. Econ. 34, 45-50.

Krinsky, I., Robb, A., 1986. Approximating the statistical properties of elasticities. Rev. Econ. Stat. 68, 715-719.

Louviere, J.J., 2006. What you don't know might hurt you, some unresolved issues in the design and analysis of discrete choice experiments. Environ. Resour. Econ. 34, 173-188.

Louviere, J., Hensher, D., Swait, J., 2000. Stated Choice Models - Analysis and Application. Cambridge University Press, Cambridge. U.K.

Mazzotta, M.J., Opaluch, J.J., 1995. Decision making when choices are complex, a test of Heiner's hypothesis. Land Econ. 71 (4), 500-515.

Poe, G.L., Giraud, K.L., Loomis, J.B., 2005. Simple computational methods for measuring the differences of empirical distributions. Am. J. Agric. Econ. 87 (2), 353-365.

Rolfe, J.C., Loch, A., Bennett, J.W., 2006. Testing benefit transfer with water resources issues in central Queensland, Australia. In: Rolfe, J., Bennett, J. (Eds.), 2006 Choice Modelling and the Transfer of Environmental Values. Edward Elgar, Cheltenham, UK.

Scarpa, R., Willis, K., 2006. Distribution of willingness-to-pay for speed reduction with non-positive bidders, is choice modelling consistent with contingent valuation? Transp. Rev. 26 (4), 451-469.

Swait, J., Adamowicz, W., 2001. The influence of task complexity on consumer choice, a latent class model of decision switching strategy. J. Consum. Res. 28, 135-148.

Van Haefen, R.H., Massey, D.M., Adamowicz, W.I., 2005. Serial nonparticipation in repeated discrete choice models. Am. J. Agric. Econ. 87 (4), 1061-1076. 